\title{
EL DERECHO A LA EDUCACIÓN: DIFICULTADES EN LAS DEFINICIONES NORMATIVAS Y DE CONTENIDO EN LA LEGISLACIÓN ARGENTINA
}

\author{
Right to Education: Normative lacks and problematic \\ definitions at the Argentine legislation
}

\author{
GUILLERMO RAMÓN RUIZ \\ Universidad de Buenos Aires / CONICET \\ gruiz@derecho.uba.ar \\ SEBASTIÁN SCIOSCIOLI \\ Universidad de Buenos Aires / CONICET \\ sebastianscioscioli@derecho.uba.ar
}

Cómo citar/Citation

Ruiz, G. R. y Scioscioli, S. (2018)

El derecho a la educación: dificultades en las definiciones normativas y de contenido en la legislación argentina. Revista Española de Derecho Constitucional, 114, 105-129. doi: https://doi.org/10.18042/cepc/redc114.04

Resumen

La Ley de Educación Nacional (2006) regula el ejercicio del derecho a la educación en Argentina. Constituye el piso federal sobre el cual la legislación de las provincias debe establecer sus regulaciones específicas en el marco del Estado federal argentino. En este trabajo se problematiza el alcance del derecho a la educación a luz de la teoría de los derechos fundamentales a efectos de precisar sus implicancias para la definición de las políticas educativas. En primer lugar, se cuestiona qué supone este derecho en términos de contenidos, alcance y exigibilidad. En segundo lugar, se describe cómo es reglamentado por la legislación de Argentina y se discute su contenido a la luz de la extensión diferenciada (por la propia ley) de la obligatoriedad escolar, lo cual repercute en el plano de los estados provinciales. Finalmente, se presentan algunas reflexiones en relación con el rol del Estado nacional y las definiciones de políticas educativas. 


\title{
Palabras clave
}

Derecho a la educación; legislación educativa; derechos humanos fundamentales; políticas educativas; rol del Estado; Argentina; federalismo.

\begin{abstract}
The National Education Act (2006) regulates the right of education in Argentina. It is the federal base on which each province should pass their specific legislation according to the Argentine federalism. This article traces and analyzes basic definitions regarding the meaning of the right to education from the human rights based approach in order to figure out its implications for public policies. Consequently, we start asking about what is meant by education as a right. Then, we describe the way in which Argentine national legislation regulates it. We focus on the differentiated extension of compulsory education designed by this legislation. Finally, we examine the uses of these categories to analyze the relationships between the National State and the educational policies.
\end{abstract}

\section{Keywords}

Right to Education; Educational legislation; Human Rights; Educational policies; Role of State; Argentina; Federalism. 


\section{SUMARIO}

I. INTRODUCCIÓN. II. LA EDUCACIÓN COMO DERECHO HUMANO FUNDAMENTAL Y DERECHO SOCIAL. III. LA LEY DE EDUCACIÓN NACIONAL: SUS DEFINICIONES SOBRE EL CONTENIDO DEL DERECHO A LA EDUCACIÓN: 1. La ley y sus referencias sobre el derecho a la educación. 2. La ley y sus omisiones sobre el derecho a la educación. IV. LA OBLIGATORIEDAD COMO CONTENIDO DEL DERECHO A LA EDUCACIÓN EN LA LEY 26206: DISCUSIONES SOBRE SU APLICACIÓN DIFERENCIAL EN LOS NIVELES PRIMARIO Y SECUNDARIO. V. CONCLUSIONES. BIBLIOGRAFÍA.

\section{INTRODUCCIÓN}

La Ley de Educación Nacional (2006) constituye actualmente el marco normativo nacional que regula el derecho a la educación en la Argentina. En su artículo primero reglamenta el ejercicio del «derecho a enseńar y aprender» tal como lo expresa el histórico art. 14 de la Constitución Nacional ${ }^{1}$ y que refleja asimismo la aspiración del poder legislativo nacional de aprobar la legislación de organización y de base para la educación conforme lo dispuesto en el inciso 19 del art. 75 del mismo texto legal. En tal sentido, la norma constitucional y su posterior desarrollo normativo constituyen el piso federal sobre el cual las legislaciones de las provincias argentinas deben establecer sus regulaciones específicas en el marco del Estado argentino. Como ley de naturaleza federal $^{2}$, la Ley 26206 implica una base innegociable y vinculante que las

1 Conforme el art. 1 de la ley, que expresa: «La presente ley regula el ejercicio del derecho de enseñar y aprender consagrado por el artículo 14 de la Constitución Nacional y los tratados internacionales incorporados a ella, conforme con las atribuciones conferidas al Honorable Congreso de la Nación en el artículo 75, incisos 17, 18 y 19, y deacuerdo con los principios que allí se establecen y los que en esta ley se determinan». El desarrollo constitucional en materia de educación también puede apreciarse, desde su texto histórico de 1853 y su reforma en 1994, en otras normas directa o indirectamente vinculadas en la Constitución.

2 La calificación de una norma como «federal» es objeto de arduos debates conceptuales y de no pocos problemas para su precisión. Ello es así puesto que, en el derecho argentino, el Congreso Nacional puede emitir diversos tipos de normas con distinto alcance y jerarquía. Debido a que la Argentina posee un «federalismo atenuado» en materia de derecho común, la legislación de derecho público y/o privado de naturaleza codificada (como el derecho comercial, derecho civil, derecho penal, derecho laboral, entre otros) 
provincias deben cumplir y que el Estado nacional está obligado a garantizar en función de los compromisos asumidos por el derecho internacional de los derechos humanos ${ }^{3}$. Sin embargo, el diseño y la aplicación de estas normas han profundizado la tendencia histórica a la diversificación dispersa en cuanto a la organización institucional y académica del sistema y así ha puesto en riesgo el goce del derecho a la educación al permitir la coexistencia de diferencias en las duraciones de los niveles educativos obligatorios dentro de su estructura académica (Ruiz, 2016). La complejidad de lo federal como régimen de gobierno de Argentina tiene efectos diferenciales a la hora de aplicar las reformas escolares en el ámbito de las jurisdicciones provinciales, lo cual requiere de un rol promotor del derecho a la educación por parte del Estado (Scioscioli, 2015). Es aquí donde resulta importante el análisis del desarrollo argumentativo que la Ley 26206 evidencia en relación con la caracterización que hace del derecho a la educación como un derecho social.

En este trabajo se problematiza precisamente el término «derecho a la educación", que aparece en la legislación de base de la educación argentina a luz de la teoría de los derechos fundamentales, a efectos de precisar su alcance e implicancias para la definición de las políticas educativas. Para ello, en primer lugar, se cuestiona qué supone este derecho. En segundo lugar, realizamos un encuadre de la Ley de Educación Nacional desde las bases constitucionales de la educación argentina y del derecho internacional de los derechos humanos.

constituye una atribución propia y exclusiva de la legislatura federal, pero su interpretación y aplicación queda en manos de los poderes judiciales provinciales o locales (en estos casos, las legislaturas locales solo pueden dictar normas de procedimiento o procesales aplicables a sus territorios). Las leyes federales se definen por exclusión, es decir, de manera residual, como aquellas que la propia Constitución determina como tal en razón de su materia (en temas como nacionalidad, naturalización, falsificación de la moneda, supremacía de la Constitución... entre otras) o por derivar del ejercicio de las competencias o atribuciones de los órganos federales. La interpretación y aplicación de este tipo de normas corresponde a los tribunales federales.

3 El derecho internacional reconoce la existencia de países con estructura federal. Sin embargo, claramente prevé que ello no debe hacer mella en el reconocimiento de los derechos en todo el territorio de aquel. Así, la Convención Americana, en su art. 28, expresamente señala que el federalismo no puede ser una excusa del Estado nacional para el incumplimiento de los derechos al interior de sus territorios. Su art. 2 complementa lo arriba dispuesto y establece la obligación del Estado parte de la adopción de las medidas de derecho interno que resulten necesarias para dar efectividad a las normas convencionales de protección, y así subsanar eventuales lagunas o insuficiencias del derecho interno, incluidas las originadas en la estructura federal a fin de armonizarlas con las normas convencionales. 
Posteriormente, se describe cómo es regulado por la legislación de Argentina y se discute su contenido a la luz de la extensión diferenciada (por la propia ley) de la obligatoriedad escolar, lo cual repercute en el plano de los estado provinciales, así como también mencionamos algunas críticas a dichas definiciones e interpretaciones sobre su aplicación. Esto último nos dará lugar a efectuar a algunas conclusiones de interés sobre el papel del Estado federal en el diseńo y aplicación de las leyes que regulan el ejercicio de este derecho.

\section{LA EDUCACIÓN COMO DERECHO HUMANO FUNDAMENTAL Y DERECHO SOCIAL}

La educación como derecho no solo está garantizada en el orden jurídico interno de un Estado de derecho, sino que forma parte también del derecho internacional de los derechos humanos, el que constituye un sistema normativo complejo creado para el establecimiento de: a) estándares internacionales y contenidos básicos (para regular derechos garantizados a todas las personas) y b) obligaciones que dichos derechos generan para los Estados hacia sus habitantes. En este sentido, como derecho humano y, en particular, como derecho social, la educación deriva en acciones positivas (es decir, prestacionales) y negativas (de no intervención) a cargo mayormente del Estado 4 .

En la tarea de conceptualizarlo, se podría tomar como punto de partida el hecho que todas las personas tienen el derecho a la educación debido a que las capacidades para interpretar el mundo y para actuar en él resultan esenciales para la vida humana. Sin embargo, al tratar de definir el concepto de derecho a la educación se pueden distinguir preguntas sustantivas de difícil elucidación y que exceden incluso el marco de lo estrictamente jurídico: ¿qué supone el derecho a la educación? Se trata de un derecho a qué. En este punto se pueden identificar tres áreas de incertidumbre (McCowan, 2013):

1) La cuestión sobre derecho a qué exactamente es el derecho a la educación, en lo que atañe a la forma, al contenido y a las experiencias involucradas por la educación escolar.

4 De acuerdo con la clasificación antedicha, según la función que los derechos fundamentales cumplan en la relación Estado-ciudadano, es posible también distinguir entre derechos de defensa (no intervención), derechos de prestación (sociales), derechos de organización y procedimiento y derechos de protección (Alexy, 2008; Scioscioli, 2015). 
2) La/s relación/es entre el derecho a la educación y los otros derechos humanos fundamentales, sobre todo cuando la asistencia a las instituciones de escolarización obligatoria supone el (potencial) cercenamiento de otros derechos humanos o bien qué otros derechos humanos no pueden ser efectivamente ejercidos; asimismo, se encuentra el problema que refiere a que la asistencia a la escuela obligatoria conlleva regímenes académicos que priorizan o promueven la meritocracia por la propia organización de la jornada y la tarea escolar

3) El alcance del derecho a la educación en lo que atañe a la vida de los seres humanos, o sea si se acaba en la etapa de asistencia obligatoria, para nińos/as y adolescentes, o si tiene el mismo contenido a lo largo de toda la vida de las personas

En relación con esta tercera cuestión, incluso algunas definiciones de instrumentos internacionales de derecho abonan la concepción de que la escolarización no agota el alcance del derecho a la educación ya que esta última «es más que una escolarización oficial y engloba un amplio espectro de experiencias vitales y procesos de aprendizaje que permiten al niño, ya sea de manera individual o colectiva, desarrollar su personalidad, dotes y aptitudes y llevar una vida plena y satisfactoria en el seno de la sociedad» (Comité de los Derechos del Niño, 2001: 5) 5 .

En lo que se refiere a las relaciones entre derechos y educación, según un informe de Lansdown (2001) se pueden identificar tres componentes involucrados:

5 La educación formal se refiere a aquella que se desarrolla en sistemas escolares de alcance masivo que se encuentran regulados de modo tal que se conforma una estructura académica en la que se pueden distinguir cursos, años, grados, agrupados en niveles educativos que abarcan desde la educación maternal, infantil o inicial hasta la educación superior universitaria. En esta regulación se estable un rango de obligatoriedad de estudios que incluye a la población infantil y adolescente. La educación no formal engloba aquellas experiencias de educación que si bien están programadas y diseñadas por la autoridad estatal, se orientan principalmente a mejorar o dotar de competencias (laborales, académicas, de alfabetización) a la población, pero por fuera de las instituciones de la educación formal que transcurre dentro de los sistemas masivos de escolarización. La educación informal, por su parte, es la que acontece a lo largo de la vida de las personas, que les permite la adquisición de valores, competencias, conocimientos a partir de la influencia educativa que pueden ejercer diferentes tipos de instituciones (museos, bibliotecas, grupos de pares, medios de comunicación, ámbitos labores... entre otros). 
— El derecho de acceso a la educación formal: para cada niño/a y joven, sobre la base de la igualdad de oportunidades, sin discriminación.

- El derecho a la calidad educativa: en el sentido de que cada estudiante pueda acceder a una educación formal que le permita desarrollar todo su potencial, aprovechar sus oportunidades y favorecer el desarrollo humano.

— El derecho al respecto dentro del ambiente de aprendizaje: para cada estudiante sobre la base de la dignidad y la diversidad en las cuales se asientan los derechos humanos.

En términos de contenido, en las últimas siete décadas, desde la planificación y la instrumentación de las políticas educativas, se ha tendido a pensar el derecho a la educación en función de determinados indicadores, tales como que cada nińo/a acceda a una plaza o vacante en las escuelas, por determinada cantidad de años, con un conjunto de recursos asignados para su escolarización obligatoria, así como la provisión de un cuerpo de docentes con determinado nivel de formación.

Sin embargo, incluso si se consideran sinónimos a la educación y a la escolarización, resulta muy dificultoso comprender la complejidad que posee la experiencia escolar para los diferentes grupos sociales que asisten a las instituciones educativas, en las diferentes edades y de acuerdo con los propósitos específicos de la educación formal en cada uno de sus niveles. Desde el derecho internacional de los derechos humanos es claro definir al derecho a la educación en lo que atañe a las instituciones, acciones y recursos que deben proveerse a las personas; también resultan claras las estipulaciones que se refieren a la duración obligatoria de la experiencia escolar y de los tiempos escolares según los diferentes niveles de la educación escolar. No obstante, lo que no resulta claro es cómo se definen los procesos escolares que deben desarrollarse en cada uno de los anteriores componentes. Es más, en algunos contextos (países, regiones o culturas) falta mayor precisión o persiste la ausencia de acuerdos sobre los propósitos de la educación formal, o bien se destacan potenciales conflictos entre el Estado, los padres y los agentes de la educación. Estas indeterminaciones dan cuenta de que en materia educativa suelen conjugarse aspectos políticos, pedagógicos, ideológicos, entre muchos otros, y que dificultan la definición y precisión de qué (y cómo) se enseña y se aprende ${ }^{6}$.

6 Las definiciones curriculares a su vez han estado afectadas por disputas sobre qué constituye el contenido escolar que debería distribuirse en los diferentes niveles educativos. Estas disputas resultan tanto de tipo epistemológico (en relación con que si existe algún tipo de conocimiento objetivamente válido a ser distribuido de forma 
Si tomamos al curriculum como indicador del contenido del derecho a la educación veremos que se torna problemático su definición como tal: problema que podríamos pensarlo como el derecho a conocer qué. En cierta medida los instrumentos internacionales de derechos humanos han procurado establecer entre los Estados algunos contenidos en valores y principios tales como aquellos que se enumeran en el artículo 26 de la Declaración Universal de los Derechos Humanos, que en verdad son mayormente el producto de acuerdos internacionales ante los horrores ocurridos en la Segunda Guerra Mundial y que más que contenidos escolares conceptuales constituyenvalores y principios a ser inculcados en la escolarización. Por otra parte, sitratamos-como ejemplo-de restringir el alcance del contenido curricular básico para el derecho a la educación a conocer el acervo cultural de la sociedad en la cual se vive, es decir, las tradiciones, lenguajes, costumbres, cabría pensar si efectivamente todas las tradiciones de una sociedad son compatibles con el enfoque de los derechos humanos fundamentales como marco para encuadrar a la educación como uno de ellos.

En otro sentido, si se intenta conceptualizar al derecho a la educación a partir de resultados o estándares educativos tanto nacionales como internacionales, podrían identificarse también algunas limitaciones. En primer lugar, que los estándares una vez definidos, si bien pueden ser concebidos como indicadores sobre cuáles serían los aprendizajes valorados por una sociedad —en un período determinado-, ellos por si solos, no crean las condiciones idóneas para el aprendizaje allí donde no existan con antelación. En segundo lugar, hay problemas en la especificación de los resultados educativos

homogénea al conjunto de la población escolar) como también estrictamente político, en la medida en que se denunciaba que el conocimiento escolar es una expresión de la dominación social (Young, 2008) o bien un instrumento funcional para la generación de una hegemonía que permita mantener el statu quo (Apple, 2012). Sin embargo, más allá de estas disputas epistemológicas o políticas, es muy difícil justificar el carácter universal del currículo escolar, en el sentido de concebir la posibilidad de que exista un conocimiento escolar intrínsecamente válido debido a que las definiciones curriculares están muy influidas por la cultura y el lenguaje (McCowen, 2013). Es más, si concentramos la definición curricular en competencias fundamentales para el desarrollo humano desde la niñez hasta la adultez, como puede ser la lectocomprensión, debemos recordar la diversidad de las estructuras que poseen los idiomas. En este sentido, puede mencionarse — por ejemplo - el dato que proveen los buenos traductores, quienes sostienen que existen expresiones intraducibles de una lengua a otra (Dussel, 2016). Ello precisamente evidencia la dificultad de definir temas o contenidos sustantivos (como la alfabetización) para la vida de las personas en contenidos universales de la escolarización masiva y obligatoria. 
deseables en términos del derecho a la educación en aspectos tales como: el nivel de alfabetización logrado, las competencias analíticas, las habilidades de comunicación, entre otras que resultan esenciales para el desarrollo humano a lo largo de toda la vida ${ }^{7}$.

Aquí cobra relevancia también la discusión en torno a los límites de la educación formal en las sociedades contemporáneas, dado que los aprendizajes pueden acontecer en múltiples ámbitos diferentes a los escolares, y además ello puede, a su vez, representar para muchos el criterio para continuar la escolarización formal o bien abandonarla. Lo cual es en sí mismo un desafío para

7 El derecho a la educación supone una estrecha vinculación con los aprendizajes que las personas puedan desarrollar a través de diferentes procesos cognitivos. A su vez, garantizar el derecho a aprender de los estudiantes en términos de lo que espera la sociedad (en función de los estándares contemporáneos) supone asimismo un drástico cambio en la enseñanza que tiene lugar en las instituciones educativas. Lo cual a la vez implica cambios en la formación de los profesores, acordes con las necesidades educativas y características de los estudiantes, de los diferentes niveles de educación obligatoria. Entre esos desafíos se encuentra el desarrollo de propuestas de trabajo escolar más ambiciosas desde el punto de vista de la planificación y programación didáctica, así como de la evaluación de los aprendizajes. Dichas propuestas deberían orientarse a lograr niveles de rendimiento más efectivos, al tiempo que tendrían que contemplar los diferentes y divergentes puntos de partida de los estudiantes y sus estilos de aprendizaje. Todo ello, consecuentemente, afectaría la organización escolar, del tiempo y de las tareas que acontecen en las instituciones educativas.

Un planteamiento válido y central en esta tarea de conceptualización sobre el contenido y el alcance del derecho a la educación podría estar dado por el significado de los procesos de aprendizajes de los estudiantes (Darling-Hammond, 2001; McCowan, 2013). Ello permitiría evaluar no solo el desarrollo humano de cada estudiante, sino también cómo esos aprendizajes favorecen el desarrollo social de las personas, en cada contexto histórico y cultural en particular. Colocar el foco en los procesos desde el punto de vista del contenido del derecho a la educación supone promover el carácter activo de la enseñanza como uno de los mayores potenciales de la escolarización obligatoria (Dewey, 1970). Aspectos tales como la indagación, el diálogo, la comprensión lectora (y su desarrollo pleno de acuerdo con el desarrollo evolutivo de los estudiantes), la deliberación y la exploración de la argumentación para analizar las diferencias (en términos de perspectivas analíticas) son algunos de los procesos educacionales que podrían ser incluidos desde esta perspectiva. Consecuentemente, a su vez, prestar atención y promover estos procesos redundaría en la formación inicial de los docentes, para cada uno de los niveles escolares. Vale destacar que el otorgar centralidad a los procesos educativos no supone descuidar o negar la promoción de resultados o de estándares de formación (sin que ello necesariamente implique —a su vez- estandarizar a los estudiantes). 
los Estados en materia de las obligaciones prestacionales que tienen respecto de garantizar el ejercicio de este derecho.

\section{LA LEY DE EDUCACIÓN NACIONAL: SUS DEFINICIONES SOBRE EL CONTENIDO DEL DERECHO A LA EDUCACIÓN}

En la Constitución argentina la educación es objeto de regulación en diferentes cláusulas, algunas ya previstas en la constitución histórica de 1853, y otras que han sido incorporadas producto de su reforma en el año 1994. Es posible agruparlas conforme a las siguientes categorías:

1) Aquellas que refieren al derecho a la educación (y su contenido): en el art. 14 se reconoce a todos los habitantes el derecho de enseñar y aprender; en el art. 20, este derecho se extiende específicamente a los extranjeros; en el inciso 22 del art. 75 se incluyen con jerarquía constitucional los instrumentos internacionales de derechos humanos y que poseen disposiciones relativas al derecho a la educación ${ }^{8}$; los incisos 17 y 23 del art. 75 demarcan los alcances que posee el contenido del derecho a la educación y las medidas de acción positiva que desde la legislación nacional deben promover la igualdad. La cuestión educativa desde la perspectiva de los derechos fundamentales no ha sido extensamente atendida por la jurisprudencia nacional. Las relaciones directas e indirectas que la materia presenta con otros derechos constitucionales han sido más bien abordadas en relación con la libertad religiosa, la igualdad, el derecho a la salud... entre varios otros (Bravo, 1988; Gargarella, 2008; Gelli, 2005). ${ }^{9}$

8 Tales como el Pacto Internacional de Derechos Civiles y Políticos (art. 18), la Convención sobre la Eliminación de todas las Formas de Discriminación Racial (arts. 5. ${ }^{\circ}$ y 7.), la Convención sobre la Eliminación de todas las Formas de Discriminación contra la Mujer (art. 10) y la Convención sobre los Derechos del Nińo (art. 28), entre otros.

9 El case law de la Corte sobre el derecho a la educación en la Argentina en el nivel federal permite vislumbrar que los casos que han llegado a los tribunales han referido históricamente en mayor medida a afectaciones indirectas del derecho a la educación por la vía de la vulneración de otros derechos fundamentales, especialmente de los tradicional e indubitablemente incluidos como «derechos civiles y políticos». Los casos más emblemáticos en el tema educativo se han vinculado con situaciones de discriminación [Repetto, Fallos 311: 2272(1988); Almirón, Fallos 305: 1489(1983); Arenzón, Fallos 306:400(1984); González de Delgado, Fallos 323:2659 (2000)]; la 
2) Las que atañen a la distribución de competencias entre el Estado federal y las provincias: en este marco de distribución de competencias, resulta fundamental recordar el régimen federal de gobierno de Argentina, ya que constituye un aspecto clave para la comprensión de la legislación educativa en el plano nacional y en el de las jurisdicciones provinciales (Falleti, 2001; Scioscioli, 2015). En efecto, el federalismo da lugar a relaciones de diverso tipo y que pueden clasificarse en tres grupos: de subordinación, de participación y de coordinación (Bidart Campos, 1997). En el caso de la legislación educativa todas ellas importan. Por un lado, mientras la relación de subordinación señala, como hemos citado más arriba, el deber elemental del Estado federal en el cumplimiento del piso del derecho en todo el territorio, la relación de participación convoca a la voluntad de las provincias en la formación de la decisión del Congreso Nacional, plasmada en la Ley de Educación Nacional, de regular en materia educativa. Por el otro lado, se despliega la relación de coordinación, en tanto supone la distribución de competencias y obligaciones entre el Estado federal y los estados miembros. Sobre la base del principio que sienta el art. 121 , el art. 5 establece que las provincias son responsables de la educación primaria en sus territorios, y en el art. 75, incisos 18 y 19 se dispone que el Congreso Nacional debe «sancionar leyes de organización y de base del sistema educativo». Una interpretación armónica de estas normas junto con los arts. 124 y 125 permiten abrir camino para el desarrollo de políticas de concertación entre el Estado federal y las provincias, entre las que se incluye a la materia educativa como una competencia concurrente entre ambos niveles de gobierno ${ }^{10}$.

libertad de conciencia y de cultos [Barros, Fallos 301: 151, (1979), Castillo, CSJ 1870/2014/CS1 (2017)], régimen escolar disciplinario [Galina, Fallos 304: 391 (1982)]. Solo recientemente, la Corte ha mostrado una mayor preocupación en el cumplimiento de obligaciones o prestaciones debidas por el Estado nacional o provincial en materia educativa como derecho social [Provincia de Salta c. Estado nacional, Fallos 325:2367 (2002); Defensor del Pueblo de la Nación c. Estado nacional y Pcia. de Chaco, Fallos: 330:4134 (2007)], entre otros.

10 Aunque no en el tema educativo, la propia Corte Suprema de Justicia de la Nación ha insistido en este tiempo en la necesidad y conveniencia de reforzar un «federalismo de concertación» en Argentina. Ello supondría, en términos de la Corte, una herramienta fundamental para "garantizar un federalismo lealmente aplicado", que permita "una interacción articulada, cooperativa», y que asegure el correcto funcionamiento de los entes o consejos de composición federal - en los que participan ambos niveles de gobierno- para la solución de los conflictos o problemas 
A lo largo de la historia, el Congreso Nacional ejerció sus atribuciones en legislación educativa a través de normas con distintos ámbitos de aplicación y para diferentes niveles educativos ${ }^{11}$. Precisamente, es posible identificar en la legislación una de las herramientas más importantes para la definición de las políticas educativas, aunque debe atenderse también a la implementación de las leyes, por parte de los Gobiernos, para comprender sus implicancias. Ahora bien, conjuntamente con el ejercicio de las funciones administrativa, legislativa y jurisdiccional, se encuentra la función de gobierno o política, que se refiere a la actividad de los órganos superiores de Estado en las relaciones que hacen a la subsistencia de las instituciones que organiza la Constitución (Cassagne, 2006). Ello es importante dado que supone que el análisis de la legislación no debe descuidar el rol del Estado a través de la implementación que lleva adelante el poder ejecutivo nacional.

\section{LA LEY Y SUS REFERENCIAS SOBRE EL DERECHO A LA EDUCACIÓN}

El Estado argentino reglamentó (intensamente) el ejercicio del derecho a la educación en las últimas décadas ${ }^{12}$, y como consecuencia dispuso la extensión de la obligatoriedad escolar, lo cual incluyó un desafío particular: tornar obligatorio el nivel secundario. El contexto federal y los antecedentes de la descentralización completa de la prestación de los servicios educativos (a principios de la década de 1990) dieron lugar a diferentes aplicaciones de esta política de ampliación de la escolaridad obligatoria. Luego de varios años de fuerte

inter-jurisdiccionales. Pueden verse en este sentido los casos La Pampa c/ Mendoza s. uso de aguas, CSJ 243/2014 (50-L/CS1) (2017); Santa Fe, Fallos 338:1389 (2015), entre otros.

11 Si bien no fue hasta el año 1993 cuando se aprobó la primera ley de base para el conjunto del sistema (Ley 24195) en función de las atribuciones que la Constitución otorga al poder legislativo nacional.

12 Un breve recorrido tan solo por las normas aprobadas por el Congreso Nacional a partir de la década pasada comprende a las leyes 25864 (2003) de garantía del salario docente y 180 días de clase; 26601 (2005) de protección integral de los derechos de las nińas, los nińos y los adolescentes; 26150 (2006) conocida como ley nacional de educación sexual integral, entre otras. No puede desconocerse igualmente el desarrollo normativo histórico en el nivel federal, y en momentos de consolidación del Estado argentino, con la aprobación de leyes tales como la Ley 1420 (1884), que instaura el régimen de enseńanza primaria común, gratuita, obligatoria, universal, gradual y mixta y promovió la educación laica y la Ley 4878 (1905) de creación de escuelas nacionales en las provincias, entre otras (Tedesco, 1986). 
conflictividad social, entre los ańos 2004 y 2006, se generó un nuevo marco normativo que reemplazó al aprobado en la década de 1990: en diciembre de 2006 se aprobó la Ley 26206, de Educación Nacional (LEN) ${ }^{13}$. La aplicación ulterior de las políticas educativas se montó sobre el piso federal dispuesto por esta ley, pero en contextos jurisdiccionales diferenciados, lo cual ha redundado de manera directa sobre las posibilidades efectivas del goce del derecho a la educación (en los niveles obligatorios del sistema) en función de su localización.

Si bien la ley regula múltiples aspectos que requerirían ser tratados con detenimiento, nuestra propuesta consiste en analizar aquellos puntos que puedan tener especial impacto en términos de contenidos del derecho a la educación como derecho humano fundamental.

En tal sentido, en primer lugar, puede mencionarse al art. 2. Allí se establece que la educación es un «bien público» y un «derecho personal y social» garantizado por el Estado y, seguidamente, el art. 3 sostiene que la educación "es una prioridad nacional y se constituye en política de Estado». Si se sigue esta lógica, la ley seńala la «responsabilidad principal e indelegable» del Estado en sus distintos niveles federales (nación y provincias) de proveer educación, lo que se encuentra en sintonía con lo dispuesto en la Constitución en su art. 75 , inciso 19, ya comentado. Esta idea de responsabilidad también se encuentra a tono con la definición sobre el carácter de derecho humano que ha querido enfatizar la ley y que se refuerza con las cerca de veintidós referencias que

13 Un análisis aparte merecería el hecho que el proyecto de ley fue aprobado casi en su totalidad según el dictamen de la mayoría conformado por el Gobierno de turno sin aceptar modificaciones de ningún tipo. Otra crítica también está dada por el pobre y escaso nivel de debate que se evidenció en las dos Cámaras del Congreso federal. El primer proyecto de ley que el Gobierno nacional presentó el 16 de septiembre de 2006 tenía 139 artículos. El proyecto tuvo una segunda fase de consultas (entre septiembre y octubre) y finalmente ingresó al Senado el 16 de noviembre de 2006. En el Senado fue remitido a las comisiones de Educación, Ciencia y Tecnología, de Población y Desarrollo Humano, y de Presupuesto y Hacienda. El día 5 de diciembre de 2006 se aprobó el proyecto con modificaciones al original en una reunión conjunta de las comisiones a las que había sido remitido y un día después ( 6 de diciembre) fue aprobado en el recinto del Senado. El mismo miércoles 6 de diciembre de 2006 el proyecto pasó a la Cámara de Diputados, donde fue enviado a las comisiones de Educación y de Presupuesto y Hacienda, las que en una reunión conjunta celebrada el 7 de diciembre lo aprobaron sin modificaciones (hubo en aquella ocasión tres dictámenes en minoría). El 14 de diciembre de 2006 la Cámara de Diputados del Congreso Nacional aprobó la ley que fue publicada en el Boletín Oficial el día 28 de diciembre de aquel año. 
involucran aspectos del contenido del derecho a la educación, en términos de los principios de igualdad, libertad, autonomía, democracia, ciudadanía, entre otros valores.

Así, ello se observa en la impronta de contenidos que deben guiar a los procesos de enseńanza y de aprendizaje en sus distintos niveles y modalidades. El art. 11, inciso c, establece entre los fines de la política educativa nacional «la formación ciudadana, el respeto a los derechos humanos»; y en el inciso g se pregona «el respeto a los derechos de los niños/as y adolescentes». En el art. 27 remarca como una finalidad de la educación primaria una formación que habilite «para el ejercicio de una ciudadanía responsable». Algo similar dispone para con la educación secundaria en su art. 30, inciso $\mathrm{a}^{14}$. Es posible entender (al menos como un posible argumento a partir de este tipo de contenidos) el interés del Estado como actor responsable para con la formación autónoma y en determinados valores éticos de sus ciudadanos para así sostener la «obligatoriedad escolar» de la educación señalada en su art. 16.

Si se toma esto como ejemplo, se observa que la ley procura dotar de este modo al sistema educativo de determinados principios y valores propios de una concepción de derecho fundamental o constitucional. En varios de esos artículos también se hace hincapié en la noción de respeto a la diversidad, la interculturalidad y la inclusión. La norma destaca que el sistema educativo debe atender a las particularidades de todos, en el marco de la promoción de una educación integral e inclusiva, como señala el inciso n del art. 11, al destacar como objetivo de la política educativa «brindar a las personas con discapacidades, temporales o permanentes, una propuesta pedagógica que les permita el máximo desarrollo de sus posibilidades, la integración y el pleno ejercicio de sus derechos». Este carácter inclusivo se enfatiza en la necesidad del reconocimiento de múltiples modalidades específicas para atender a ciertos grupos de estudiantes, además del supuesto de la modalidad de educación especial recientemente señalada. Así la norma refiere también como derecho a la necesidad de prever una educación "permanente de jóvenes y adultos», la «educación rural», la "educación en contextos de encierro" y la "educación domiciliaria y hospitalaria».

En esta línea, asimismo, se hace mención en múltiples oportunidades al principio de igualdad, como en oportunidad de referirse a los valores que

14 En suma, la introducción de este tipo de contenidos obligatorios y la actualización de los núcleos de los contenidos mínimos (denominados «núcleos de aprendizajes prioritarios») ha permitido el desarrollo de nuevos diseños curriculares así como la inclusión de temas claves vinculados con desafíos actuales asociados con los valores democráticos, la perspectiva de género, el respeto por la diversidad... entre otros puntos. 
deben estar presentes en la educación (art. 8), al objetivo de la política educativa de «asegurar la igualdad de oportunidades educativas» y la promoción de eliminación de cualquier forma de discriminación (art. 11). Se advierte que el contenido de la igualdad, en las numerosas ocasiones que aparece en el articulado, no solo se forja desde una comprensión formal (como principio antidiscriminatorio, de igualdad ante la ley), sino también desde su acepción como igualdad material o real e incluso de reconocimiento (Aldao y Clérico, 2011). En este último caso, la igualdad es considerada como principio de no sometimiento ante situaciones de desigualdad fácticas, como lo representaría la garantía de la educación «intercultural bilingüe» en su art. 52 (la que se promueve tanto a los fines de preservar y fortalecer las pautas culturales de los pueblos indígenas como a los efectos de «permitir a sus integrantes desempeñarse activamente en un mundo intercultural y mejorar su calidad de vida») derivado de lo dispuesto en el art. 75, inciso 17, de la Constitución.

\section{LA LEY Y SUS OMISIONES SOBRE EL DERECHO A LA EDUCACIÓN}

Este somero análisis no exime a la ley de algunas críticas importantes en relación con la educación como derecho y sus alcances. Ello es así porque, a pesar de estos reconocimientos, subsisten vacíos y confusiones que no permiten resolver suficientemente y con precisión la pregunta inicial que formuláramos sobre qué supone el derecho a la educación. La norma no termina de avanzar en aspectos cruciales vinculados con el reconocimiento del contenido del derecho a la educación, tales como la disponibilidad, la accesibilidad, la adaptabilidad y la aceptabilidad. En verdad, un análisis riguroso acerca de qué contenidos supone la educación como derecho conforme a esta norma arroja un amasijo de notas que se destacan en algunos niveles o modalidades para luego olvidarse en otras; en algunos casos la norma reenvía o remite con frecuencia a otros textos normativos aprobados con anterioridad (y en contextos históricos y normativos diferentes), lo que dificulta severamente la integridad de tales contenidos, su interpretación y aplicación en los casos concretos ${ }^{15}$.

15 Puede tomarse como ejemplo paradigmático lo que ocurre con la controversia judicial que tramitó ante la Corte Suprema de Justicia de la Nación por el tema de la educación religiosa en el currículo oficial e impartida durante el horario de clases en las escuelas públicas de la provincia de Salta. En toda la Ley 26206 no surge en ningún momento el carácter laico de la enseñanza oficial, no obstante los desarrollos normativos históricos que expresamente abogaban por el carácter, en conformidad con la posición respecto de la relación entre el Estado y la Iglesia prevista en la Constitución Nacional. 
Así, en muchos casos, la Ley 26206 ha relegado estos temas a otras leyes (incluso anteriores, como el tema del financiamiento o la modalidad de educación técnico profesional) a políticas públicas posteriores (como la especificación programática de acciones como los planes y programas de mejora para tornar efectiva la calidad educativa declamada), o bien ha mantenido incólumes, y por ende coexistentes con la regulación actual, regímenes precedentes cuestionados desde un enfoque de derechos. Esto en particular si se piensa en diversos reconocimientos normativos y financieros a la educación privada y ocurridos en el marco de los procesos de privatización de la educación. Así, en cuanto a las regulaciones sobre la educación privada, se mantiene la misma connotación que aparecía en la Ley Federal de Educación en relación con la definición de los servicios educativos de acuerdo con el tipo de gestión. Si bien se señala que los particulares que brinden educación quedarán sujetos a la autorización, reconocimiento y supervisión de las autoridades jurisdiccionales estatales (art. 62), en el título III de la ley no resultan menores las concesiones y prerrogativas ya reconocidas por el propio texto para con dicho sector. Así, la ley avanza en la definición de los nuevos agentes con capacidad para brindar educación privada: además de la Iglesia católica y las confesiones religiosas inscriptas en el Registro Nacional de Cultos y las sociedades, se mencionan a las cooperativas, las organizaciones sociales, sindicatos, asociaciones, fundaciones y empresas con personaría jurídica y a las personas físicas; y se mantienen los mismos derechos y obligaciones establecidos en la Ley $24195{ }^{16}$. La misma continuidad aparece respecto de las remuneraciones mínimas de los docentes de instituciones educativas privadas. El art. 14, en este sentido, remarca que al sistema educativo lo integran los servicios de gestión «estatal, privada, cooperativa y social». Precisamente por ello, algunos de sus principios o líneas de acción tan importantes han requerido, para tornarse operativos, de una actividad posterior profusa a nivel infraconstitucional y legal, como las adoptadas en el ámbito del Consejo Federal de Educación ${ }^{17}$.

16 Así, se reconoce el derecho de los servicios educativos de gestión privada a evaluar y emitir certificados y títulos con validez oficial, formular planes y programas de estudio, aprobar el proyecto educativo institucional de acuerdo con su ideario y participar del planeamiento educativo, entre otros.

17 Pensemos, por ejemplo, en el rol del Ministerio de Educación nacional como un ámbito de fijación de políticas y estrategias nacionales. Entre sus funciones se previó lo dispuesto en el art. 115 de la ley: declarar la emergencia educativa para brindar asistencia de carácter extraordinario en aquella jurisdicción en la que esté en riesgo el derecho a la educación de los/as alumnos/as que cursan los niveles y ciclos de carácter obligatorio. La falta de una mayor precisión y de mecanismos dentro de la ley que 


\section{LA OBLIGATORIEDAD COMO CONTENIDO DEL DERECHO A LA EDUCACIÓN EN LA LEY 26206: DISCUSIONES SOBRE SU APLICACIÓN DIFERENCIAL EN LOS NIVELES PRIMARIO Y SECUNDARIO}

Desde la pedagogía la cuestión de la obligatoriedad de la escolarización se entrelaza con las funciones de disciplinamiento y normalización de la escuela. Tanto el currículo escolar como la organización de la enseñanza se estructuran para organizar la desigualdad entre los escolares y no tanto para convivir con la diversidad. Según Gimeno Sacristán, «el mecanismo de normalización que define el éxito y la exclusión se vio reforzado en el momento en que la escolaridad se hizo realmente obligatoria para todos» (2000: 76). Con ello se estructuró la escolarización sobre la base de una ordenación lineal de períodos que se corresponden con una secuencia de contenidos y fragmentos del currículo. Al respetar el orden de los aprendizajes sugerido, se construye una idea de progreso lineal que se percibe como natural y exigible a todos. De esta forma, cuando la escolarización se volvió obligatoria, comenzaron a identificarse aquellos casos que no lograban alcanzar las metas que la propia escuela había diseñado para ellos, es decir, comenzó a instalarse el concepto de fracaso escolar, que afecta naturalmente a los que se encuentran dentro de las escuelas.

Cuando se extiende la obligatoriedad al nivel posprimario, puede ocurrir que los mecanismos de normalización para jerarquizar a los estudiantes y sus desempeños provoquen problemas mayores. Las políticas educativas instrumentadas por los Estados occidentales a partir de la década de 1950 promovieron la expansión de la enseńanza secundaria a través de las denominadas reformas comprensivas en los Estados europeos, o de las políticas de ampliación de la cobertura en la región latinoamericana. Ello acompañó, y en parte respondió, a las exigencias sociales de mayores niveles de educación para el conjunto de los grupos sociales de cada país. Sin embargo, la expansión de la cobertura del nivel secundario se realizó con enfoques curriculares que la orientaron a ser congruente y funcional tanto para el ingreso al nivel universitario cuanto para dotar de competencias para la empleabilidad de los graduados de la escuela secundaria. Ahora bien, en la medida en que se volvió obligatoria, la educación secundaria pasó a conformar una educación general de nivel posprimario. Por ello debería ser comprendida como válida para

garantizasen su aplicación ha tornado esta cláusula en una norma prácticamente programática de uso discrecional por el poder político nacional de turno, y que hasta el momento nunca ha sido utilizada. 
todos. No obstante, si la educación secundaria también es el nivel previo del superior y se le exige un carácter propedéutico académico, requiere un currículo peculiar y grados de exigencia específicamente orientados a satisfacer la formación ulterior.

En el caso argentino en particular, la reforma prevista por la Ley de Educación Nacional establece el carácter obligatorio del nivel secundario. Sin embargo, esta decisión no es equivalente para el conjunto del sistema educativo nacional, ya que la misma ley prevé diferentes duraciones de los niveles primario y secundario y con modalidades diversas (y contenidos curriculares distintos). Así, en lo que concerniente a la estructura académica del sistema, la norma derogó la Ley $25195^{18}$ y dispuso el retorno a las denominaciones «Educación Primaria» y «Educación Secundaria», con la distinción que prevé la coexistencia de dos posibles estructuras académicas en función de su duración (art. 134): una opción de seis años de duración para el nivel primario y otros seis años para el nivel secundario; otra posibilidad que contempla siete años de duración para la educación primaria y cinco años para la secundaria. El federalismo sumó otro factor de complejidad,

18 La Ley 24195 (Ley Federal de Educación) modificó la estructura histórica del sistema educativo argentino y creó dos niveles nuevos: la Educación General Básica (EGB) y la Educación Polimodal. El primero — junto con el último ańo de la Educación Inicial- era obligatorio. Sin embargo, la organización del tercero de los ciclos de la EGB fue aplicado en cada jurisdicción provincial de manera diferente. Es más, de las veinticuatro provincias, dos no aplicaron esta reforma en la estructura académica y mantuvieron la preexistente (a la Ley 24195). Ello dio lugar a una fuerte diferenciación interna del sistema educativo nacional, en cuanto a duraciones de los ciclos y de los niveles de la educación obligatoria, que afectó los contenidos de la enseñanza, los resultados de los aprendizajes y también a los docentes que trabajaban en cada uno de los niveles educativos. La aplicación fue crítica y cuestionada y generó las condiciones políticas para la derogación de esta ley trece años después de su aprobación.

La resistencia provino desde los sindicatos docentes, la comunidad educativa en general, en un contexto de fuerte conflictividad en la segunda mitad de la década de 1990 que dio lugar a una extensa protesta frente al Congreso Nacional en torno a una "carpa blanca», que consistió en una toma de la Plaza del Congreso por parte de los docentes de los diferentes niveles que se extendió durante 1003 días entre el 2 de abril de 1997 y 30 de diciembre de 1999. Además de los reclamos por mayor presupuesto educativo, a la Ley 24195 se le cuestionó sus orientaciones hacia la privatización, la provincialización y descentralización propias de la moderna derecha y de sus propuestas educativas. Estas críticas a las políticas derivadas de la aplicación diferencial de la estructura académica prevista por dicha ley generaron las condiciones políticas para su derogación en el año 2006. En relación con dichas críticas a la Ley Federal de Educación véase, entre otros, Paviglianiti (1995) y Senen González (2001). 
dado que las veinticuatro jurisdicciones provinciales optaron por estas dos opciones de modo diverso (véase Apéndice). Esto dio lugar a situaciones muy complejas de resolver, entre ellas el paso de un nivel educativo a otro que poseen diferentes duraciones. De las veinticuatro jurisdicciones, doce de ellas adoptaron una Educación Primaria de siete años, y cinco años de Educación Secundaria; mientras que otras doce jurisdicciones definieron seis años de duración para cada nivel (primario y secundario). Aquí cabe destacar que ambos niveles poseen diferentes propósitos formativos (la formación básica para el nivel primario; la formación propedéutica y para el trabajo para el nivel secundario). Por consiguiente, no resultaría equivalente, desde el punto de vista del principio de igualdad material, que el mismo sistema educativo contemple estas diferencias en los ańos de la escolarización obligatoria en función de las provincias donde la población resida. Otro problema destacable está dado por los pasajes de niveles cuando los estudiantes asisten a sistemas de diferentes jurisdicciones con distintas duraciones ${ }^{19}$. Esta aplicación diferencial de la estructura se agudiza en particular por las adaptaciones del denominado tercer ciclo de la Educación General Básica (que formaba parte de la enseñanza obligatoria según la Ley Federal de Educación), así como de la Educación Polimodal (que no era obligatoria).

Precisamente, si había algo que la Ley 26206 debía resolver era esta diferenciación en las duraciones de las ahora denominadas «educación primaria» y «educación secundaria». Sin embargo, lo que dispone la ley es la formalización de la diferencia, ya que permite a las provincias argentinas optar por una de las dos alternativas que se prevén en el art. 134. Esta disímil duración merece destacarse en función de los diferentes propósitos de enseñanza que poseen los dos

19 El problema del pasaje entre niveles educativos resulta muy notorio en el área metropolitana de Buenos Aires, la cual está conformada por la Ciudad Autónoma de Buenos Aires y los municipios limítrofes (equivalentes a los ayuntamientos españoles) que pertenecen a la Provincia de Buenos Aires. Sin constituir una entidad administrativa integrada, esta megalópolis alcanza un total de población superior a los doce millones de habitantes (Instituto Nacional de Estadística y Censos, 2003 y 2010). Muchos estudiantes de la Provincia de Buenos Aires, donde la escuela primaria se extiende seis años, al concluir el sexto año de escolarización obtienen su certificado de nivel primario concluido, pero si aspiran a ingresar a una escuela secundaria de la Ciudad de Buenos Aires al año siguiente, deben asistir al séptimo año de la escuela primaria, ya que en esta última jurisdicción la Educación Primaria tiene una duración de siete años. En consecuencia, al año subsiguiente obtienen un segundo certificado de nivel primario (que se suma al que habían obtenido en la Provincia de Buenos Aires) y entonces estarán en condiciones de iniciar la escolarización secundaria en el ámbito de la Ciudad Autónoma de Buenos Aires. 
niveles en términos de formación de los estudiantes, lo cual redunda en el alcance del contenido del derecho a la educación. La Ley de Educación Nacional es muy profusa en las definiciones de dichos propósitos para cada uno de los niveles (arts. 27 y 30, para los niveles primario y secundario respectivamente). La ampliación de la obligatoriedad del nivel secundario resulta así cuestionable, porque no resuelve la diferenciación educativa preexistente, sino que la convalida al permitir diferentes duraciones de dos de los niveles que conforman la educación obligatoria, confunde los fines y propósitos formativos de cada uno (que no son equivalentes) y genera un complejo mecanismo de reconocimiento de trayectorias, títulos, equivalencias de estudios y la movilidad de los alumnos a partir de su puesta en marcha. Todo esto tiene consecuencias para el diseño curricular de los niveles primario y secundario, así como para el desarrollo profesional de los docentes que trabajan en ambos niveles.

A este diseño se debe sumar las definiciones referidas al gobierno del sistema educativo bajo un sistema federal débil. En efecto, la Ley 26206 mantiene los tres niveles de administración y toma de decisiones y apela a la concertación en el ámbito del Consejo Federal de Educación $(\mathrm{CFE})^{20}$ como mecanismo central para la definición y aplicación de políticas educativas. Según la ley, las decisiones de este Consejo son de cumplimiento obligatorio, cuando la Asamblea así lo disponga, de acuerdo con la reglamentación de este. Esta cuestión quedó definida por el Reglamento de Funcionamiento del Consejo Federal de Educación, cuyo art. 11 establece que la Asamblea Federal del CFE se pronuncia a través de dos categorías de decisiones: a) resoluciones y b) recomendaciones. Aun así, la Ley 26206 deja, sobre la base de parámetros mínimos de articulación (y con algunas deficiencias observables en el funcionamiento del Consejo Federal de Educación), a las autoridades provinciales que determinen el diseño de los planes de estudios y demás aspectos de la definición curricular. Ello, por ende, puede reforzar algunos de los efectos indeseados de la anterior norma, al ampliar y formalizar una desarticulación horizontal dentro de la estructura académica. Entre esos problemas figura la posibilidad de que se refrende la validez nacional de títulos que se correspondan con estudios y contenidos muy diferenciados en

20 El Consejo Federal de Educación fue creado como un organismo de coordinación del sistema en el año 1972, tuvo un rol secundario hasta la aprobación de la Ley 24195 en 1993. A partir de entonces cobró centralidad en la definición de las políticas educativas en el contexto del Estado federal argentino, ya que refleja los intereses de los diferentes niveles de gobierno además de las orientaciones políticas de sus integrantes. En la actualidad integran este Consejo el Ministerio Nacional de Educación, las autoridades educativas de las veinticuatro jurisdicciones provinciales (ministros, directores generales de educación, según corresponda) y tres integrantes del Consejo de Universidades. 
el plano curricular, o bien que no se incluyan suficientemente los contenidos obligatorios pautados en el nivel federal, entre otros puntos. Todo ello parece no ser consistente con una formación integral, igualitaria y de calidad para el conjunto de la población escolar, tal como es garantizada por la Constitución y lo demarcan las definiciones previstas en el tema por los instrumentos internacionales de derechos humanos y los informes de organismos internacionales como el Comité de Derechos Económicos Sociales y Culturales. ${ }^{21}$

\section{CONCLUSIONES}

A partir del rol preponderante que la Constitución Nacional de Argentina le asigna al Estado en materia educativa, se derivan obligaciones referidas al respeto, cumplimiento y garantía de la educación como derecho fundamental. Este conglomerado de obligaciones supone, entre otros aspectos, que los Estados adopten una política nacional acompañada de un plan de acción detallado para el ejercicio del derecho. Vale aclarar que en la obligación de cumplir no solo quedan incluidas las obligaciones de prestación y de protección, sino también aquellas de desarrollo normativo, como el dictado de normas para reglar procedimientos, para organizar un sistema administrativo y de justicia eficaz y de acceso igualitario, entre otras. Esta intensidad normativa para la educación en la Argentina ha sido una constante, si bien se acrecentó a lo largo de las décadas de 1990, de 2000 y de 2010. Sin embargo, el mayor reconocimiento normativo no se ha traducido por sí solo en una mayor vigencia y exigibilidad del derecho a la educación en los términos precisión de contenidos educativos tal como fuera problematizado previamente.

Los efectos sistémicos negativos en cuanto a la organización institucional y académica del sistema, en todos sus niveles, han limitado u obstaculizado el goce del derecho a la educación por parte del conjunto de la población, de manera equivalente. Aunque merece ser objeto de otro análisis particular, no puede dejar de destacarse que la complejidad de lo federal como régimen de gobierno de Argentina tiene efectos diferenciales a la hora de aplicar las reformas escolares. La ausencia de un Estado promotor del derecho a la educación sobre la base de la igualdad de oportunidades, principio consagrado por las bases constitucionales, ha dado lugar una marcada diferenciación del sistema educativo en el plano de las jurisdicciones provinciales. Esta crítica se profundiza con el argumento ya referido y vinculado con la delegación en organismos burocráticos definiciones de aspectos claves de la política educativa y propios

21 Puede verse en tal sentido, la Observación General n. ${ }^{\circ} 13$ (1999) del propio Comité. 
de la competencia legislativa (como en el caso de las competencias reconocidas al Ministerio nacional en el art. 115, inciso b). Como vemos, en estos temas se vuelve a apelar al consenso a través de un órgano federal como el Consejo Federal de Educación, que, aunque la ley destaca que puede haber decisiones de cumplimiento obligatorio para todas las provincias, no se precisa dentro de la ley en qué circunstancias ello ocurrirá.

El ciclo de reformas iniciado en 2003 se ha presentado como un intento de dotar de mayor homogeneidad a la organización institucional y académica del conjunto del sistema educativo argentino. Sobre todo, a partir de la aprobación de la legislación nacional en 2006 en conjunto con otras normas nacionales que regulan diferentes aspectos de la educación formal. No obstante, la subsistencia de vacíos o imprecisiones como la habilitación de dos opciones de estructura académica para la educación obligatoria no permite vislumbrar una resolución congruente e integral para la diferenciación educativa estructural.

Es de destacar que el desarrollo normativo existente en la Argentina en materia de educación es un aspecto sumamente positivo. Sin embargo, frente a la aparición de la Ley de Educación Nacional hubiera sido deseable también que la norma en su gran extensión de más de 140 artículos hubiera acompañado el alto nivel de declamaciones, principios y propósitos que se enuncian con la correspondiente precisión acerca de las medidas o políticas a adoptar para la consecución de tales metas. Máxime cuando no es menor el caudal normativo de principios y contenidos previstos y asumidos en los instrumentos internacionales de derechos humanos y que conforman, como señaláramos, el bloque de constitucionalidad federal que de acuerdo con el art. 75, inciso 22, integra el derecho argentino. Pese al impacto positivo de los procesos de internacionalización del derecho público y de constitucionalización del derecho privado, queda aún mucho de la tarea más de tipo doméstica interna a cargo de los órganos políticos (tanto de los poderes ejecutivo, legislativo y judicial) para que adopten las acciones necesarias para precisar en políticas públicas y medidas concretas sobre cómo llevar adelante y tornar más exigibles los contenidos básicos y curriculares en materia educativa. Es necesario aún interpelar al Congreso Nacional para que, juntamente con la Administración nacional, procure la adopción de las medidas legislativas y de otro carácter, así como los recursos necesarios, que contribuyan a superar los déficits y falta de acuerdos previstos en la ley. En todo ello también los tribunales de justicia ocupan un rol en tanto deben estar atentos a las omisiones e incumplimientos defectuosos que se denuncien, especialmente frente a reclamos de naturaleza colectiva y estructural, llamen a la responsabilidad de tales instituciones y dispongan el restablecimiento de los pisos federales y fundamentales de los contenidos del derecho cuando estos son desconocidos o insuficientemente garantizados. 


\section{Bibliográfica}

Aldao, M. y Clérico, L. (2011). Nuevas miradas de la igualdad en la jurisprudencia de la Corte Interamericana de Derechos Humanos: la igualdad como redistribución y como reconocimiento. Revista de Estudios Constitucionales, 9 (1), 157-198. Disponible en: https://bit.ly/2S0QLzK.

Alexy, R. (2008): Teoría de los derechos fundamentales [trad. Carlos Bernal Pulido]. Madrid: Centro de Estudios Políticos y Constitucionales.

Apple, M. W. (2012). Poder, conocimiento y reforma educacional. Buenos Aires: Miño y Dávila; EdUNLPam.

Bidart Campos, G. J. (1997). Manual de la Constitución reformada. Buenos Aires: Ediar.

Bravo, H. F. (1988). Bases constitucionales de la educación argentina. Buenos Aires: Centro Editor de América Latina.

Cassagne, J. C. (2006). Derecho administrativo. Buenos Aires: Lexis Nexis, Abeledo Perrot.

Comité de Derechos Económicos Sociales y Culturales. (1999). Observación General n. ${ }^{\circ} 13$. Disponible en: https://bit.ly/2q1EyxZ.

Comité de los Derechos del Niño (UNICEF). (2001). Observaciones generales. Disponible en: https://uni.cf/2FAmfcK.

Darling-Hammond, L. (2001). El derecho de aprender. Crear buenas escuelas para todos. Barcelona: Ariel.

Dewey, J. (1970). Democracia y educación. Buenos Aires: Losada.

Dussel, I. (2016). Epílogo. En G. Ruiz y F. Acosta, F. (eds.). Repensando la educación comparada: lecturas desde Iberoamérica. Entre los viajeros del siglo XIX y la globalización (pp. 181-186). Barcelona: Octaedro.

Falleti, T. (2001). Federalismo y descentralización educativa en Argentina. En E. Calvo y J. M. Abal Medina (eds.). El federalismo electoral argentino. Buenos Aires: Eudeba.

Gargarella, R. (coord.) (2008). Teoría y crítica del derecho constitucional. Buenos Aires: Abeledo Perrot.

Gelli, M. A. (2005). Constitución de la Nación Argentina. Comentada y concordada. Buenos Aires: La Ley.

Gimeno Sacristán, J. (2000). La obligatoriedad escolar: su sentido educativo y social. Madrid: Morata.

Instituto Nacional de Estadística y Censos (INDEC) (2003). ¿Qué es el Gran Buenos Aires? Buenos Aires: INDEC. Disponible en: https://bit.ly/2yoIXQq.

- (2010). Censo Nacional de Población, Hogares y Viviendas 2010. Disponible: en: https:// bit.ly/2QVxEpA.

Lansdown, G. (2001). Progress in implementing the rights in the convention. En S. N. Hart, C. P. Cohen, M. F. Erickson y M. Flekkoy (eds.). Children's Rights in Education (pp. 37-59). London: Jessica Kingsley.

McCowan, T. (2013). Education as a Human Right. Principles for a Universal Entitlement to Learning. London: Bloomsbury.

Paviglianiti, N. (1995). La Ley Federal de Educación como elemento de regulación de la realidad educacional Argentina. Sus orientaciones hacia la privatización, la provincialización y 
descentralización de las decisiones en los Poderes Ejecutivos y el retiro del Gobierno Nacional del financiamiento de la educación pública. Buenos Aires: OPFYL.

Ruiz, G. (2016). La educación secundaria obligatoria en el marco de las reformas educativas nacionales. Regulaciones federales y politicas jurisdiccionales. Buenos Aires: EUDEBA.

Scioscioli, S. (2015). La educación básica como derecho fundamental. Implicancias y alcances en el contexto de un Estado Federal. Buenos Aires: EUDEBA.

Senen González, S. (2001). Argentina: Centro y Periferias en la Reforma Educativa: Macroproyectos y Micropolitica (1993-1999). Buenos Aires: Presentación LASA. Disponible en: https://bit.ly/2OA6Y0E.

Tedesco, J. C. (1986). Educación y sociedad en la Argentina (1880-1945). Buenos Aires: Ediciones Solar.

Young, M. (2008). Bringing Knowledge Back In. London: Routledge.

\section{APÉNDICE}

Tabla 1. Opciones de estructura académica, según jurisdicciones provinciales y normativa respectiva

\begin{tabular}{|c|c|c|c|}
\hline \multicolumn{4}{|c|}{ Opciones de estructura académica } \\
\hline \multicolumn{2}{|c|}{$\begin{array}{l}7 \text { años de nivel Primario y } \\
5 \text { años de nivel Secundario }\end{array}$} & \multicolumn{2}{|c|}{$\begin{array}{l}6 \text { años de nivel Primario y } \\
6 \text { años de nivel Secundario }\end{array}$} \\
\hline Jurisdicción & Normativa & Jurisdicción & Normativa \\
\hline $\begin{array}{l}\text { Ciudad } \\
\text { Autónoma de } \\
\text { Buenos Aires }\end{array}$ & Ley n.o 898 de $2002^{1}$ & Buenos Aires & $\begin{array}{l}\text { Ley Provincial de } \\
\text { Educación n. }^{\circ} \\
13688 \text { de } 2007\end{array}$ \\
\hline Chaco & $\begin{array}{l}\text { Ley Provincial n. } \\
6478 \text { de } 2010\end{array}$ & Catamarca & $\begin{array}{l}\text { Ley Provincial de } \\
\text { Educación n. }{ }^{\circ} 5381 \\
\text { de } 2013\end{array}$ \\
\hline Jujuy & $\begin{array}{l}\text { Ley Provincial n. } \\
5807 \text { de } 2013\end{array}$ & Córdoba & $\begin{array}{l}\text { Ley Provincial de } \\
\text { Educación n. } \\
9870 \text { de } 2010\end{array}$ \\
\hline La Rioja & $\begin{array}{l}\text { Ley Provincial de } \\
\text { Educación n. }^{\circ} \\
8678 \text { de } 2009\end{array}$ & Corrientes $^{2}$ & $\begin{array}{l}\text { Ley Provincial n. } \\
5813 \text { de } 2008\end{array}$ \\
\hline Mendoza $^{3}$ & Sin normativa & Chubut & $\begin{array}{l}\text { Ley de Educación } \\
\text { Provincial n. } \\
91 \text { de } 2010\end{array}$ \\
\hline
\end{tabular}




\begin{tabular}{|c|c|c|c|}
\hline \multicolumn{4}{|c|}{ Opciones de estructura académica } \\
\hline \multicolumn{2}{|c|}{$\begin{array}{l}7 \text { años de nivel Primario y } \\
5 \text { años de nivel Secundario }\end{array}$} & \multicolumn{2}{|c|}{$\begin{array}{l}6 \text { años de nivel Primario y } \\
6 \text { años de nivel Secundario }\end{array}$} \\
\hline Jurisdicción & Normativa & Jurisdicción & Normativa \\
\hline Misiones $^{4}$ & Resolución n. ${ }^{\circ}$ 289/07 & Entre Ríos & $\begin{array}{l}\text { Ley Provincial de } \\
\text { Educación n. }^{\circ} \\
9890 \text { de } 2008\end{array}$ \\
\hline Neuquén & $\begin{array}{l}\text { Ley Provincial de } \\
\text { Educación n. }^{\circ} \\
2945 \text { de } 2014\end{array}$ & Formosa & $\begin{array}{l}\text { Ley de Educación n. } \\
1613 \text { de } 2014\end{array}$ \\
\hline Río Negro & $\begin{array}{l}\text { Ley Orgánica de } \\
\text { Educación de la } \\
\text { Provincia de Río Negro } \\
\text { n. } 4819 \text { de } 2012\end{array}$ & La Pampa & $\begin{array}{l}\text { Nueva Ley de } \\
\text { Educación Provincial } \\
\text { n. } 2511 \text { de } 2009\end{array}$ \\
\hline Salta & $\begin{array}{l}\text { Ley de Educación de la } \\
\text { Provincia n. } \\
7546 \text { de } 2008\end{array}$ & San Juan & $\begin{array}{l}\text { Ley Provincial de } \\
\text { Educación n. } \\
\text { 1327-H de } 2015\end{array}$ \\
\hline Santa Cruz & $\begin{array}{l}\text { Ley de Educación } \\
\text { provincial n. } \\
3305 \text { de } 2013\end{array}$ & San Luis & Decreto n. ${ }^{\circ} 154 / 08$ \\
\hline Santa Fe & Decreto n. ${ }^{\circ} 2885 / 07$ & $\begin{array}{l}\text { Tierra } \\
\text { del Fuego }\end{array}$ & $\begin{array}{l}\text { Resolución ministerial } \\
\text { n. } 3306 / 10\end{array}$ \\
\hline $\begin{array}{l}\text { Santiago } \\
\text { del Estero }\end{array}$ & $\begin{array}{l}\text { Ley de Educación n. } \\
6876 \text { de } 2007\end{array}$ & Tucumán & $\begin{array}{l}\text { Ley Provincial de } \\
\text { Educación n. }^{\circ} \\
8391 \text { de } 2010\end{array}$ \\
\hline
\end{tabular}

\section{Total: 12 jurisdicciones}

Total: 12 jurisdicciones

${ }^{1}$ Ciudad Autónoma de Buenos Aires. Esta ley establece la extensión de la escolaridad según la estructura académica histórica de siete años de Educación Primaria y cinco de Secundaria (seis y en algunos casos siete en las ofertas técnicas).

${ }^{2}$ Corrientes: Es una ley de tres artículos a través de la cual adhiere en todos sus términos a la Ley de Educación Nacional. La opción de estructura fue definida por el Decreto n. 222/08.

3 Mendoza: un proyecto de ley obtuvo la media sanción de diputados en diciembre de 2014, pero el Senado lo desaprobó en febrero de 2015.

${ }^{4}$ Misiones: se presentó un proyecto de ley en la legislatura, pero encontró fuertes rechazos de los sindicatos docentes.

5 Tierra del Fuego: había establecido esta opción en la Resolución n. ․ 2484/07.

Fuente: Ministerio de Educación de la Nación Argentina. Datos actualizados a diciembre de 2017. 